\title{
Quality Management Systems as a key element for company strategy selection - case study
}

\author{
Piotr Nowotarski ${ }^{1, *}$, Jerzy Pasławski ${ }^{1}$, and Aleksandra Kadler ${ }^{1}$ \\ ${ }^{1}$ Poznan University of Technology, Institute of Structural Engineering pl. M. Skłodowskiej-Curie 5, \\ 60-965 Poznan, Poland
}

\begin{abstract}
Term quality can be defined as the implementation of specific requirements, having its source in the expectations and needs of customers, users of products or services and their buyers. In constructions sector quality is crucial at each and every phase of the process beginning with design ending with the use of the building. There exist many different methods and tools related to quality, Lean Management, Agility, which can enhance construction process. One of such methods is SWOT analysis that can be helpful in determining the current condition of the company performing it. Article presents brief description of the quality concept and introduction to the SWOT method. It is illustrated with the example of analysis performed in company from the construction sector related to design and production of wooden trusses showing which strategy would be most appropriate for the company to execute taking into account its current condition.
\end{abstract}

\section{Introduction}

The first concepts of quality assurance in enterprises, mainly in the field of production management appeared at the beginning of XX century. Their rise was caused by the growing industrialization, increasing production capacity of the factories operating at that time and the growing complexity of the manufactured products. The following years brought new techniques and tools as well as the beginnings of standardization in the field of quality systems. Documents were developed - standards - in which, among others, instructions on how to proceed not only to detect but also to prevent errors [1].

In one of the standards - ISO 9000 definition of quality can be found according to which quality is a "degree to which a set of inherent characteristics fulfils requirement" [2].

It can therefore be said that quality is directly connected with meeting requirements, expectations and needs of customers, users of products or services and their buyers. The task of meeting these requirements belongs to suppliers and producers. Using a number of tools and methods, they can effectively perform their work, while having full control over the degree of its correctness - which is understood as being in accordance with the client's expectations. Data collection and analysis enables the possibility to react in case of errors and problems as well as eliminate them at source. An indispensable element of quality

\footnotetext{
*Corresponding author: piotr.nowotarski@put.poznan.pl
} 
assurance is striving for its continuous improvement. For this purpose the concept of quality management has just been created.

The activities related to quality management are mainly directed at managers, because as participants in the production or service provider, have the greatest impact on the efficiency of the entire process and people directly performing its job. The correct use of their potential, strengths and talents has a significant impact on the quality of the final product. It is especially important in the construction sector processes [3].

Among the treatments falling within the scope of quality management, we can distinguish [4]:

- creating a pro-quality culture;

- planning the resources needed to achieve quality objectives;

- setting the company's quality goals and monitoring the level of their fulfilment;

- defining the responsibilities and responsibilities (tasks) of employees and organizational units for achieving quality objectives;

- creating a system of interpersonal communication;

- motivating employees to get involved in achieving quality goals;

- documenting the requirements and the level of their fulfilment;

- keeping an account and analysing quality costs;

- creating a platform for communication between the enterprise and the environment in matters related to quality problems.

All of the above mentioned aspects are important from the end client point of view and company who owns the process. The thing which bind them together is company management strategy in which client's point of view, as well as current company market position taken into account. According to authors tool which can help in determining proper strategy could be SWOT analysis which is technique used for analyse manage strategic process [5].

Crucial aspect of performed analysis is company's approach to the quality. To one of the 3 fathers of quality [6]: Crosby, quality means "conformance to requirements" [7]. Quality must be defined in measurable and clearly stated terms to help the organization take action based on tangible targets, rather than on bunch, experience, or opinions. Deming, does not define quality in a single phrase. He asserts that the quality of any product or service can only he defined by the customer. Quality is a relative term that will change in meaning depending on the customer's needs [8]. Juran defines quality as "fitness for use.'* He stresses a balance between product features and products free from deficiencies. As used by Juran, the word "product" refers to the output of any process, and that includes goods as well as services [9].

Nowadays researchers point the importance of quality, especially for the construction sector where it (quality) stands together with the cost, and time [10].

The aim of this article is to present SWOT analysis method, which helps in choosing the most appropriate strategy for development of the organization based on the Quality Management practises in the construction industry sector. What is more authors focus on pointing out crucial further recommendations for company to develop and gain success on the global construction market. Article is summed up with the conclusions presenting the most important observations taken during study.

\section{SWOT Analysis}

The name of this method is derived from the acronym of words: strengths, weaknesses, opportunities, threats [11]. It belongs to one of the longest-used methods of examining the 
company's internal situation and its position in relation to the competitive environment. The SWOT analysis is a comprehensive method, and thanks to the simplicity of the study, it is also very popular, applicable in various sectors and at many levels of decision making in the company [12]. It originates from the business management discipline and has been widely applied to a broad array of disciplines [13].

Basic assumptions of the SWOT analysis were developed in the 1950s and 1960s by a group of business consultants and scientists working at Harvard Business School. They are then described as "Business Policy: Text and Cases". [14]

Internal analysis is used to designate and assess material and non-material factors that can support the development of an organization or harm its operation, both current and future. The SWOT method is a way of strategic analysis, an algorithm for multilateral assessment of internal and external factors that affect the development potential and the current condition of an organization, company or program [15].

The starting point for the SWOT analysis is the proper recognition of the following factors $[16,17]$ :

- Opportunities - positive external factors - identification of opportunities consists in finding strategic factors in the environment surrounding the organization, which decide about maintaining its position or further development.

- Threats - external negative factors - it is necessary to clarify the major factors occurring in the environment that make it difficult to maintain the position or development of the organization.

- Strengths - positive internal factors - in order to correctly identify strengths one should have knowledge about the analysed organization. The deeper the knowledge of the subject of the analysis, the more effective the result will be. The strengths depend on the type of organization being analysed, in particular its qualifications and resources.

- Weaknesses - internal negative factors - the identification of weaknesses has a similar course as the analysis of strong websites and is the result of knowledge of the subject being studied. In most cases, weaknesses arise from the various shortages of qualifications or resources of the organization.

The SWOT analysis consists of examining four situations answering the following questions [11]:

\section{Maxi - maxi (SO)}

"Can a specific strength allow me to take advantage of a given opportunity?"

It consists in using the strengths of the organization, e.g. a strong reputation on the market to strengthen external opportunities, e.g. to squeeze new market areas.

\section{Maxi - mini (ST)}

"Can a specific strength limit the given threat?"

It is based on limiting the adverse impact of the environment using the company's dominant strengths, such as: the ability to innovate on a current basis, a high level of quality, efficient improvement of processes related to customer service;

\section{Mini - maxi (WO)}

"Does the specific weakness limit the possibility of using a given opportunity?"

It concerns the impact that internal weaknesses (e.g. problems in relations with the client) have on the potential to strengthen opportunities, e.g. building strong competition in a specific environment.

\section{Mini - mini (WT)}

"Does the specific weakness increase the threat?" 
The company operates surrounded by threats that it cannot overcome due to the lack of equivalent strengths. An example of such a situation is, for example, the emergence of so-called negative quality spiral.

Described method in the construction industry can be powerful tool for the strategic planning of the company and with some fuzzy set theory modification can be even in better assisting the formulation of proper strategies [18]. Authors are of the opinion that the most important feature of SWOT analysis is it simplicity, which allows for use of it at different level in the process and in the company. It is especially important in the construction sector, where majority of people involved in actual execution of the process are workers performing their work, who, when comes to the improvements, should understand the idea of proposed methods and solutions.

\section{Case study}

Authors decided to perform analysis on the company which was established in 1991 in Poland. From the very beginning, it was related to the wood industry. In the first period, the company specialized in lumber trade, and currently operates as a certified producer of wooden roofs, ceilings and frame houses.

\subsection{Process Description}

The process chosen for the analysis is related to designing and execution of prefabricated truss structure and consists of several stages. It starts from receiving an inquiry from the customer. The merchant (contact with the client) in consultation with the designer preliminarily assesses whether the given project is feasible in the form of barbed wire plates, used in the company and whether the deadline set by the client is possible to meet. If so, the client is asked to complete the necessary project documentation if the query was incomplete, which includes: the last floor plan, all sections through the building, roof projection and the location of the object. The façades are also helpful for illustrative purposes.

On the basis of the documents sent, the designer sets the architectural layers, and hence the load on the truss. Then model the walls in the program, give the spacing of girders, complements the data on load coverage and climatic conditions. The next step is to model the truss itself. On the basis of the preliminary design project prepared by the constructor, an offer is prepared, which is then presented to the client.

When the customer accepts the offer, the details of the contract are determined, which is then signed. Prior to the implementation of the truss, an assembly and executive project is prepared. It consists of drawings showing the location of the truss elements and concentrations on the plan, as well as all details and details, along with a technical description enabling easy assembly. The project prepared in this way is sent to the customer in order to confirm the compliance of the design assumptions with the actual state of the construction site, to eliminate potential errors related to changes introduced during the construction, which the customer did not notify the contractor of the truss.

After the client has sent back the acceptance, the list of trusses, barbed plates, connectors, braces and files for the saw, i.e. the so-called workshop documentation, which is sent from the design office to the prefabrication plant. In the production hall, using individual programmable saws, individual elements are cut, which are then connected by means of a hydraulic press to the barbed plates. 
The finished girders are loaded onto the transport car. On the assembly site, the girders are unloaded and placed on the walls using a crane. Usually they are mounted directly on the rims and connected with it by means of anchors. Special washers are used between the rim and the wood. The attached trusses are connected by means of concentrations.

After the assembly is completed, the customer is given the so-called as-built documentation (approvals, approvals, declarations, certificates). The customer is obliged to sign the assembly acceptance protocol. The signed protocol ends the implementation process.

\subsection{SWOT analysis and results}

Based on the FMEA, Ishikawa, 5Whys, the tools of Lean Management and Quality Management, as well as direct conversation with the company workers there were 4 groups of factors defined according in the Figure 1.

Secondly authors confront the internal and external factors found, by examining their mutual influence. For this purpose, a zero-one system were used, in which the occurrence of interaction between the factors marked with the number 1 , but no dependence - the number 0 .

\begin{tabular}{|c|c|c|c|c|c|}
\hline \multicolumn{6}{|c|}{ SWOT Factors } \\
\hline Sym. & Weight & Internal Factors & Sym. & Weight & External Factors \\
\hline & 1,00 & STRENGHT [S] & & 1,00 & OPPORTUNITIES [O] \\
\hline S1 & 0,07 & $\begin{array}{l}\text { a high level of technology corresponding to } \\
\text { European standards }\end{array}$ & 01 & 0,12 & company development and production increase \\
\hline $\mathrm{S} 2$ & 0,10 & price competitiveness & $\mathrm{O} 2$ & 0,11 & the opportunity to compete in the industry market \\
\hline S3 & 0,07 & highly qualified team of designers & O3 & 0,09 & increase in the number of regular customers \\
\hline \$4 & 0,07 & comprehensive offer (design, production, assembly) & O4 & 0,10 & $\begin{array}{c}\text { increase in the popularity of the type of construction } \\
\text { produced }\end{array}$ \\
\hline S5 & 0,09 & large share in the regional market & 05 & 0,07 & technology development \\
\hline S6 & 0,05 & clear division of duties in individual departments & 06 & 0,09 & long-term cooperation with a design office \\
\hline S7 & 0,08 & $\begin{array}{c}\text { large trust and frequent company instructions } \\
\text { among clients }\end{array}$ & O7 & 0,11 & $\begin{array}{l}\text { establishment of a branch in another area of the } \\
\text { country }\end{array}$ \\
\hline S8 & 0,10 & high quality of trusses & OS & 0,09 & low reliability of the competition's work \\
\hline s9 & 0,09 & timely execution of orders & 09 & 0,11 & enlargement of the Staff amount \\
\hline $\mathbf{S} 10$ & 0,10 & many years of experience on the market & & & \\
\hline S11 & 0,08 & use of the highest quality raw materials & & & \\
\hline S12 & 0,10 & $\begin{array}{c}\text { possession of international product quality } \\
\text { certificates }\end{array}$ & & & \\
\hline & 1,00 & WEAKNESSES [W] & & 1,00 & THREATS [T] \\
\hline W1 & 0,11 & long waiting times for assembly & $\mathrm{Tl}$ & 0,14 & high production costs \\
\hline W2 & 0,13 & $\begin{array}{l}\text { small attachment to the company of production and } \\
\text { assembly workers }\end{array}$ & $\mathrm{T} 2$ & 0,13 & the appearance of strong competition \\
\hline W3 & 0,11 & too few employees & T3 & 0,09 & $\begin{array}{l}\text { change in trends (decrease in popularity of } \\
\text { technology) }\end{array}$ \\
\hline W4 & 0,09 & long waiting time for offers in the season & T4 & 0,08 & $\begin{array}{c}\text { increase in unemployment (decrease in the number } \\
\text { of investments built) }\end{array}$ \\
\hline W5 & 0,12 & narrow range of specialization & T5 & 0,12 & seasonality of production growth \\
\hline W6 & 0,14 & no quality management system in the company & T6 & 0,11 & a small number of specialized designers \\
\hline W7 & 0,14 & lack of quality control of products & T7 & 0,10 & logs of trust among customers \\
\hline W8 & 0,08 & frequent changes to the work schedule & T8 & 0,11 & change of the company owner \\
\hline W9 & 0,08 & non-compliance with health and safety rules & T9 & 0,12 & clogeness to competition \\
\hline
\end{tabular}

Fig. 1. Identified SWOT factors

Results of this analysis are presented in Figure 2. The list showed that by far the largest number of interactions $(170)$ and the highest sum of products $(15,90)$ has the maxi-maxi 
strategy. This means that the company is dominated by strengths, the importance of which is important for the company's development. In combination with the large opportunities in its environment, the company may apply an aggressive strategy of further activity, based on strong expansion and diversified development.

Nearly identical results ended with the analysis of the maxi-mini (no. of interactions: 120 and sum of products: 11,82) and mini-mini (no. of interactions: 116 and sum of products:11,28) situation. This indicates a real possibility for the company to limit the impact of external threats by using its strengths and the importance of weaknesses in their enhancement.

\begin{tabular}{|c|c|c|}
\hline & OPPORTUNITIES & THREATS \\
\hline \multirow{3}{*}{ STRENGHTS } & Aggressive strategy (maxi-maxi) & Conservative strategy (maxi-mini) \\
& Number of interactions & Number of interactions \\
& 170 & 120 \\
& The sum of products & The sum of products \\
& 15.90 & 11.82 \\
\hline \multirow{2}{*}{ WEAKNESSES } & Competitive strategy (mini-maxi) & Defensive strategy (mini-mini) \\
& Number of interactions & Number of interactions \\
& 92 & 116 \\
& The sum of products & The sum of products \\
& 9.86 & 11,28 \\
\hline
\end{tabular}

Fig. 2. Results and strategy for analysed company

The lowest values of the number of interactions (92) and the sum of products $(9,86)$ were achieved by the mini-maxi strategy, which should be interpreted as a small dependence between the weaknesses of the company and its ability to use existing opportunities.

It has to be noted that indicated in the analysis weakness: lack of the quality management systems pays the important role in the current company situation since more and more focus is nowadays paid to the QMS being implemented in the companies - also in construction sector. Having implemented QMS can have positive impact not only on the organization itself, but also on the company-client and company -supplier direction which directly influence the position on the market of analysed company.

\section{Conclusions}

Analysis of the presented process revealed both weak and strong sides of the company. By pointing out problems and examining their importance several main problems that threaten the proper execution of the roof truss were examined.

Bearing in mind the great potential of the company, which has been demonstrated by the SWOT analysis, it is proposed to use an aggressive strategy as part of planning future activities. The company has the opportunity to conquer new markets, not only Polish but also foreign ones, and to increase production if it uses its strengths wisely.

In details, SWOT analysis conducted for the company taken into account showed that:

a) the enterprise has a chance to develop not only on the Polish market, but also to expand its activity to foreign markets. Bearing in mind the cost of producing a truss in Poland and the quality offered by the company, there is a great chance of 
expanding into European markets, even in spite of the popularity and availability of precast concrete truss technology in other European countries.

b) Introduction ISO 9001 standard can definitely help in proper organization of the processes in the company as well as can influence the position on the market.

c) the company is struggling with the lack of involvement among manual workers, which manifests itself lack of interest in training, frequent staff changes or absenteeism from work.

d) despite the lack of knowledge or application of quality management systems, the company has many strengths. In the opinion of clients, the company is characterized by high quality of manufactured beams, which translates into high trust and frequent recommendations of the company's services.

The advantages mentioned above based on the SWOT analysis, according to which the aggressive strategy of conquering new markets and developing presented directions is the best strategy for further action for the company.

Authors are planning further investigations in presented research area with special attention to the processes improvement synergy with the use of Lean, Quality 4.0, and Agile Management principles in SME companies, which can lead to the significant continues improvement of construction processes.

\section{Acknowledgements}

The publication was created with the support of statutory funds of Institute of Structural Engineering at Poznan University of Technology

\section{References}

1. A. Mazur, A., H. Gołaś, H. Zasady, metody i techniki wykorzystywane w zarzadzaniu jakościa. (Poznań University of Technology, Poznań 2010)

2. ISO standard 9000:2015- Quality management system - Fundamentals and vocabulary

3. Z. Ma, S. Cai, N. Mao, Q. Yang, J. Feng, P. Wang, Construction quality management based on a collaborative system using BIM and indoor positioning. Automation in Construction, 92, 35-45 (2018)

4. A. Hamrol, Zarządzanie i inżynieria jakości. (Wydawnictwo naukowe PWN , Kraków, 2017)

5. S. Khaba, C. Bhar, C. Quantifying SWOT analysis for the Indian coal mining industry using Fuzzy DEMATEL. Benchmarking: An International Journal, 24(4), 882-902 (2017)

6. J.G. Suarez, Three Experts on Quality Management: Philip B. Crosby, W. Edwards Deming, Joseph M. Juran (Total Quality Leadership Office Arlington V, 1992)

7. P.B. Crosby, Q. I. Free, The art of making quality certain. (NY: New American Library, 1979)

8. W. E. Deming, Out of the Crisis. MIT press (2000)

9. J. Juran, G. M. Gryna, Juran's Quality Control Handbook. (NY: McGraw-Hill 1988)

10. M. Gajzler, K. Zima, Evaluation of planned construction projects using fuzzy logic. International Journal of Civil Engineering, 15(4), 641-652 (2017)

11. M Szczęsna, D. Klimecka-Tatar, D.. Analiza SWOT w zakładzie produkującym cement. Archiwum Wiedzy Inżynierskiej, 2, 17-19, (2017)

12. K. Cholewicka-Goździk, Opłacalność jakości. Problemy Jakości, (7), 7-12 (2009) 
13. H. Yuan, A SWOT analysis of successful construction waste management. Journal of Cleaner Production, 39, 1-8 (2013)

14. K. Woźniak, M. Sołtysik, Analiza SWOT online: https://mfiles.pl/pl/index.php/Analiza_SWOT (accessed October 11th, 2018)

15. Ł. Szałata, J. Zwoździak,. Analiza SWOT jako podstawowe narzędzie w zarządzaniu środowiskiem. Rocznik Ochrona Środowiska (Annual Set The Environment Protection), 13, 1105-1114 (2011)

16. J. Nazarko, J. Ejdys, K. Halicka, A. Magruk, Ł. Nazarko, A. Skorek, Application of Enhanced SWOT Analysis in the Future-oriented Public Management of Technology. Procedia Engineering, 182, 482-490 (2017)

17. B. Igliński, A. Iglińska, G. Koziński, M. Skrzatek, and R. Buczkowski, "Wind energy in Poland - History, current state, surveys, Renewable Energy Sources Act, SWOT analysis", Renewable and Sustainable Energy Reviews 64, 19-33 (2016)

18. M Gunduz, M.T. Birgonul, M. Ozdemir, Development of a safety performance index assessment tool by using a fuzzy structural equation model for construction sites. Automation in Construction, 85, 124-134 (2018) 